\title{
Pediatric aseptic lower leg fracture nonunion
}

\author{
Christian von Rüden ${ }^{1,2,3}$. Sven-Oliver Dietz ${ }^{4} \cdot$ Peter Schmittenbecher ${ }^{5} \cdot$ Francisco F. Fernandez $^{6}$. Justus Lieber ${ }^{7}$. \\ Björn Wilkens $^{8} \cdot$ Matthias Rüger $^{9} \cdot$ Dorien Schneidmueller $^{1}$
}

Received: 21 September 2020 / Accepted: 10 November 2020 / Published online: 2 December 2020

(c) The Author(s) 2020

\begin{abstract}
Purpose Lower leg nonunion in pediatric patients is a rarity. Therefore, eight European pediatric trauma units retrospectively analyzed all patients younger than 18 years suffering lower leg fractures resulting in aseptic nonunion.

Methods Thirteen children and adolescents less than 18 years old ( 2 girls and 11 boys) diagnosed with aseptic nonunion of the tibia and/or fibula were evaluated. In all patients, epidemiological data, mechanism of injury, fracture configuration, and the initial treatment concept were assessed, and the entire medical case documentation was observed. Furthermore, potential causes of nonunion development were evaluated.

Results The mean age of patients was 12.3 years with the youngest patient being seven and the oldest being 17 years old. Open fractures were found in six out of thirteen patients (46\%). Nonunion was hypertrophic in ten and oligotrophic in three patients. Mean range of time to nonunion occurrence was $7.3 \pm 4.6$ months. Nonunion healing resulting in complete metal removal was found in 12 out of 13 patients (92\%), only in one case of a misinterpreted CPT type II osseous consolidation could not be found during the observation period. Mean range of time between surgical nonunion revision and osseous healing was 7.3 months as well.

Conclusion If treatment principles of the growing skeleton are followed consistently, aseptic nonunion of the lower leg remains a rare complication in children and adolescents. Factors influencing the risk of fracture nonunion development include patient's age, extended soft tissue damage, relevant bone loss, and inadequate initial treatment.
\end{abstract}

Keywords Nonunion $\cdot$ Pseudarthrosis $\cdot$ Lower leg $\cdot$ Tibia $\cdot$ Fibula $\cdot$ Pediatric $\cdot$ Children $\cdot$ Adolescents

\section{Introduction}

Fracture nonunion is difficult to treat and represents a challenge for the treating surgeon as well as it is a physical and psychological burden for the young patient. There is a general consensus that regardless of patients' age, fracture

Christian von Rüden

christian.vonrueden@bgu-murnau.de

1 Department of Trauma Surgery, BG Unfallklinik Murnau, Professor Küntscher Str. 8, 82418 Murnau, Germany

2 Department of Trauma Surgery, Sports Orthopaedics and Pediatric Traumatology, Klinikum Garmisch-Partenkirchen, Garmisch-Partenkirchen, Germany

3 Institute for Biomechanics, Paracelsus Medical University, Salzburg, Austria

4 Department of Orthopaedics and Traumatology, University Medical Center, Johannes Gutenberg-University, Mainz, Germany healing depends on a number of factors such as the complexity of the fracture, blood supply to the fracture site, bone stability, existing inflammation and existing preconditions [1-3]. The management of fracture nonunion in long bones remains a hot topic. In adults, the incidence of fracture nonunion ranges from $15 \%$ for Gustilo grade II fractures to over
5 Department of Pediatric Surgery, Städtisches Klinikum Karlsruhe, Karlsruhe, Germany

6 Department of Orthopaedic Surgery, Olgahospital, Klinikum Stuttgart, Stuttgart, Germany

7 Department of Pediatric Surgery and Pediatric Urology, University Children's Hospital of Tuebingen, Tübingen, Germany

8 Department of Pediatric Surgery and Pediatric Urology, Krankenhaus St. Elisabeth und St. Barbara, Halle/Saale, Germany

9 Pediatric Orthopaedics and Traumatology, University Children's Hospital Zurich, Zurich, Switzerland 
$80 \%$ for Gustilo grade IIIB fractures [4-6]. Although reliable data is not available for children and adolescents, the microvascular circulation and osteoblast activity are considered to be essential biological factors independent of patients' age [7]. In addition, the organization of the fracture hematoma and preparation phases and especially the cellular organization phase play an important role [8]. In pediatric fractures, these biological factors compete and complete each other in fracture healing, so that overall development of nonunion is very rare $[9,10]$. In this respect, this topic receives little or no attention in the relevant literature on pediatric traumatology $[10,11]$. Sporadic lower leg fracture nonunion is reported in individual case series in adolescents with adultlike physique following various different surgical treatment concepts [12-17]. Most of these cases involve adolescents over 10 years of age [18]. In the existing literature, lower leg nonunion in children mainly affects complicated fractures, which are accompanied by a clear bone defect as well as massive soft tissue injuries and therefore also inflammation [19-22]. In several other cases, open reduction and internal fixation was performed. Even in the presence of the abovementioned unfavorable factors it is claimed that in most cases of fracture nonunion in children and adolescents it is a consequence of incorrect treatment [22-24]. Interestingly, publications on the conservative treatment of closed lower leg fractures in children and adolescents do not address nonunion development [9]. It may be assumed that a certain number of unreported cases exist and that the rate of lower leg fracture nonunion in children and adolescents is higher than described in the literature.

This article provides a basic overview on factors leading to aseptic lower leg fracture nonunion in children and adolescents as well as a series of cases including current treatment concepts.

\section{Patients and methods}

Eight European pediatric trauma units retrospectively analyzed all patients with open epiphyseal plates with lower leg fractures resulting in aseptic nonunion. Since lower leg nonunion in pediatric patients is very rare, there was no limitation as to how old the cases were. Thirteen children and adolescents less than 18 years old ( 2 girls and 11 boys) diagnosed with aseptic nonunion of the tibia and/or fibula were evaluated. Patients with nonunion due to initially diagnosed congenital causes or to tumors as well as patients with nonunion following infection-related pathological fractures were excluded from the study. In all patients, gender, age, mechanism of injury, fracture configuration, and initial treatment concepts were assessed. Furthermore, range of time between initial fracture treatment and occurrence of nonunion was evaluated. Preoperative, intraoperative, and postoperative anterior-posterior (AP) and lateral radiographs as well as the entire medical case documentation were observed. In each case, radiographic findings were evaluated, nonunion was classified according to the system described by Weber and Cech [25], and potential causes of nonunion development were evaluated.

\section{Results}

An overview of patient data and course of injury in each case is provided in Table 1 . The mean age was $11.5 \pm 3.5$ years with the youngest patient being seven and the oldest being 17 years old. In regards to age distribution, none of the patients was younger than 7 years. Mean age of patients with nonunion following open fracture was $10.7 \pm 2.3$ years and in patients with nonunion following closed fractures $10.7 \pm 3.7$ years. Mechanism of injury was a bicycle accident in five patients, a traffic accident as pedestrian in three patients, a scooter accident in three patients, and a collision during soccer play in another two patients. According to the nonunion classification system provided by Weber and Cech [25], nonunion was hypertrophic in 10 cases and oligotrophic in three cases. According to the Gustilo and Anderson classification [26], open fractures were found in six out of thirteen patients (46\%). Initial conservative treatment was performed in three closed fractures. Closed reduction and external fixation was used in three open fractures and in another case of a closed fracture. In three cases, initial treatment included closed reduction and intramedullary nailing. In one case, closed reduction and elastic stable intramedullary nailing and in one other case combined screw and Kirschner wire fixation was performed. In the remaining case, open reduction and internal fixation (ORIF) using a small fragment plate was done. The mean range of time to nonunion was $7.3 \pm 4.6$ months (mean \pm standard deviation). The potential reason for development of nonunion in each patient is provided in Table 1. Definitive surgical revision included locking compression plating (LCP) combined with autologous cancellous bone grafting in six patients (Fig. 1a-d), reamed tibial exchange nailing in three patients, elastic stable intramedullary nailing in one patient (Fig. 2a-e) and external fixation methods in two patients (Fig. 3a-f) [27, 28]. In one of those three patients with external fixation tibial nonunion initially was considered to be aseptic. In the further clinical course when surgical revision failed it was diagnosed as a congenital pseudarthrosis of the tibia (CPT) type II according to the Crawford classification instead of a common tibial shaft nonunion [29]. Nonunion healing resulting in complete metal removal was achieved in 12 out of 13 patients (92\%), only in the case of CPT type II no osseous consolidation was obtained in the observation 


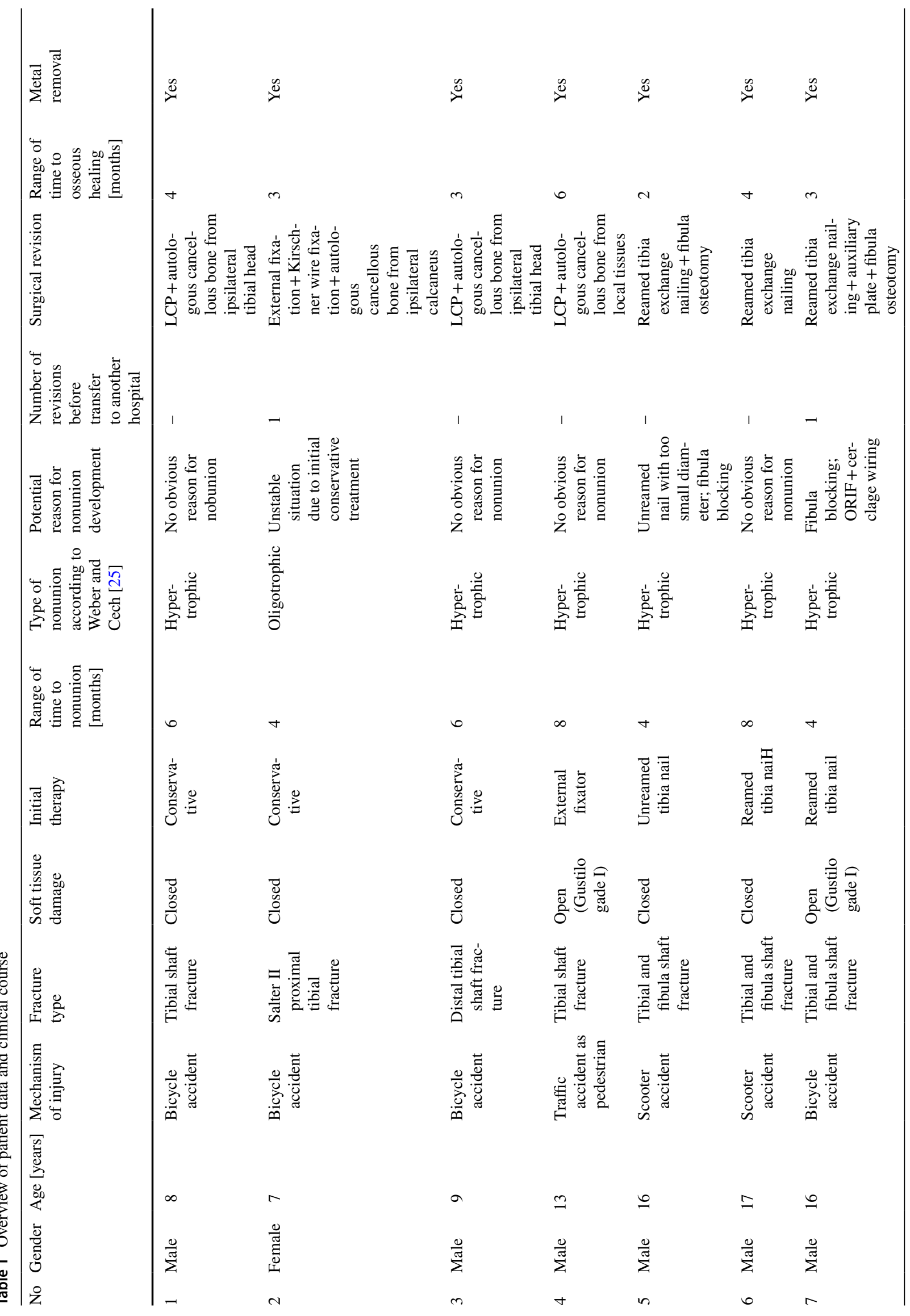




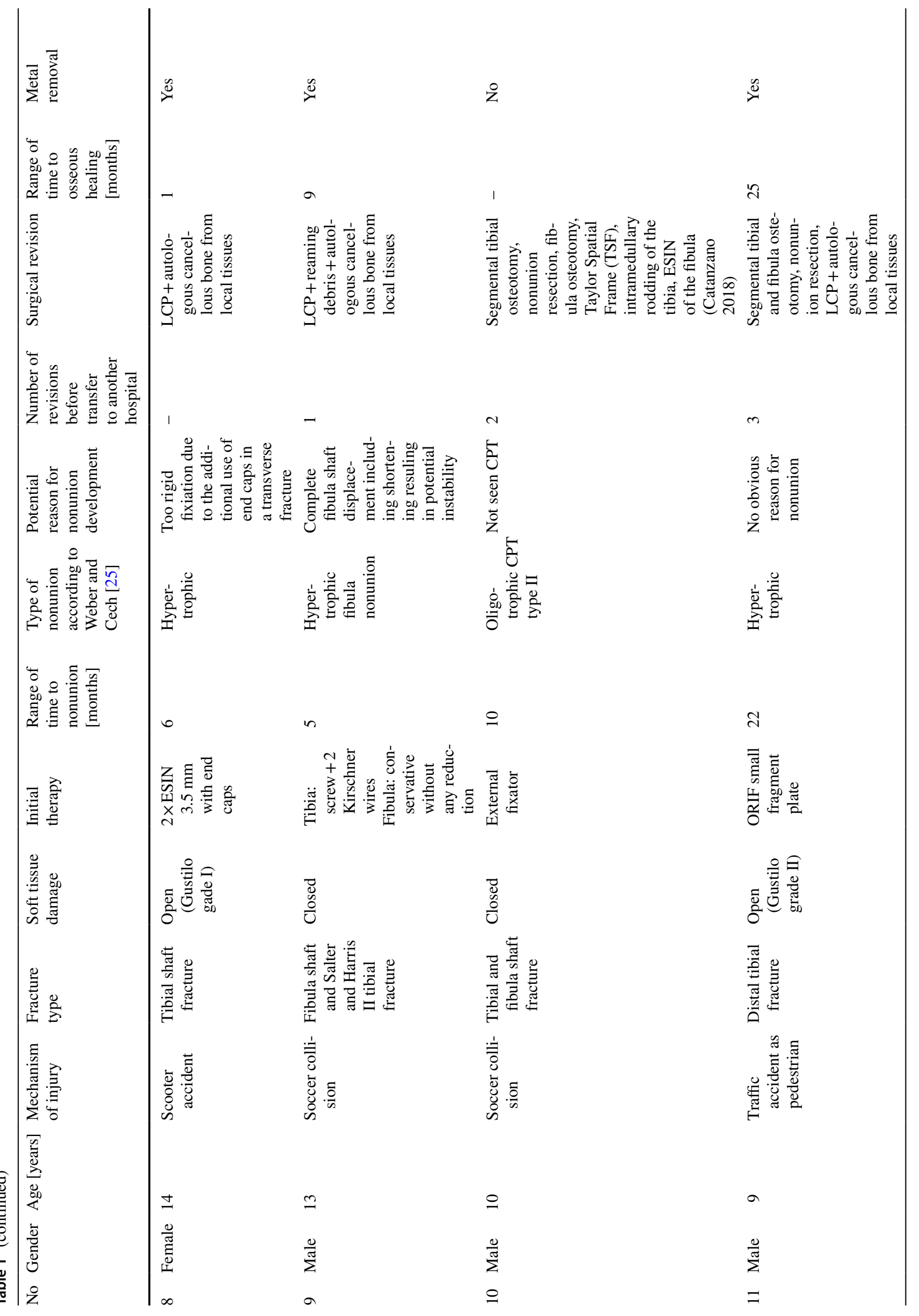




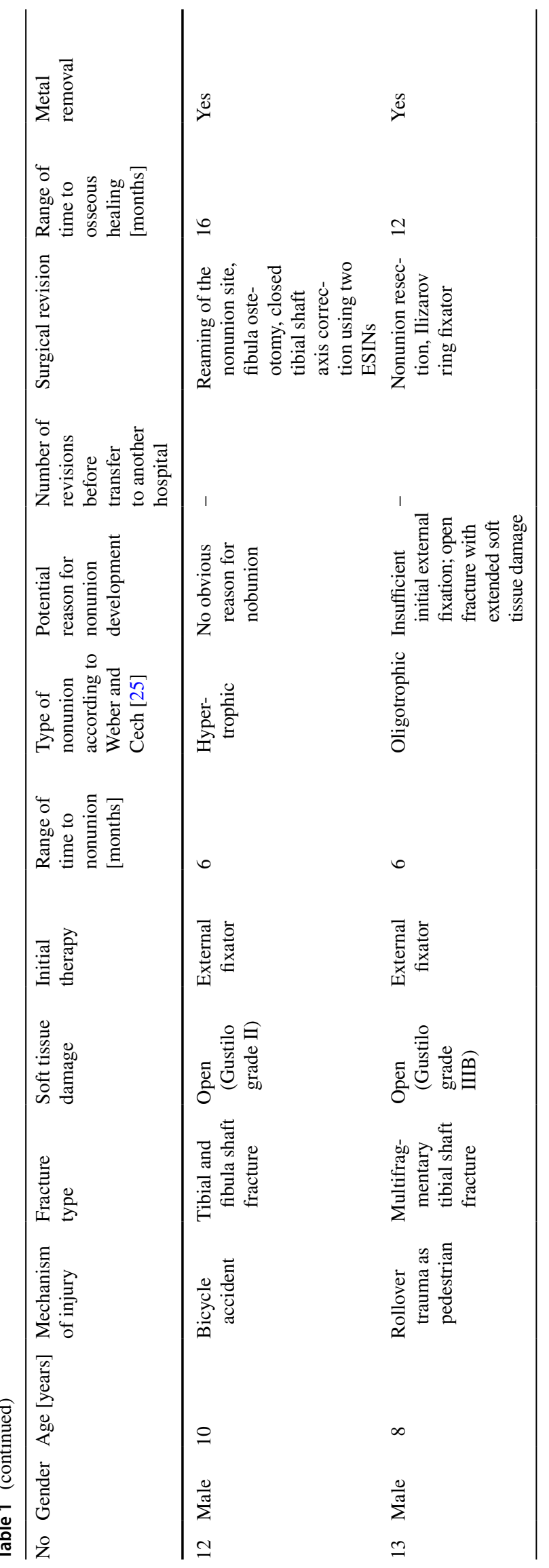

period. The mean range of time between nonunion revision and osseous healing was 7.3 months.

\section{Discussion}

Fracture nonunion is a rare complication in fractures of long bones where the growth plates are not yet closed. In children under 12 years of age this complication is seen even less frequently [30]. Age is considered to be one of the main factors for developing of nonunion in adolescents. From 12 years upwards, delayed fracture union or nonunion was seen in similar orders of magnitude comparable to those in adults $[15,31]$. Furthermore, it could be demonstrated that delayed union and nonunion formation did not occur below the age of six years and that there was a significant difference in healing rates before and after this age. In further investigations it was observed that the majority of nonunion occurred in adolescents between 12 and 16 years of age [9, 32]. In our patient collective mean age was 12 years with the majority of patients older than 12 years. In this respect, our results confirm the current literature.

The rate of open fractures in the current study was almost $50 \%$, which represents another unfavorable factor for developing a lower leg nonunion [15]. Besides, a trend towards a more frequent occurrence of nonunion in the lower extremity compared to the upper extremity was seen [9]. Regarding the question of the influence of closed or open fractures, this factor seems to have significantly more importance in adolescents than in adults [33]. The risk of nonunion formation in children and adolescents with open fractures appears to be significantly higher than in closed fractures. After growth completion in closed epiphyseal growth plates, biomechanical reasons for nonunion formation are increasingly coming to the fore. While in children with conservatively treated closed tibial fractures the development of nonunion only plays a subordinate role, in adolescents with an adult-like physique and closed growth plates the rate of nonunion appears to be of the same order of magnitude as in adults. However, in children with open tibial fractures, nonunion rates do not appear to be of the same order of magnitude as in adults, especially not in children with relevant segmental bone defects and excessive skin-soft tissue injuries if the fracture is correctly treated [22, 24, 32, 34, 35]. One reason might be that the immature skeleton has an enormous potential to form new bone when the biologic and mechanical environment is favorable [11].

Undoubtedly, some genetic and cytogenetic changes necessary for fracture healing are associated with the development of fracture nonunion, although many aspects of the pathogens are still unclear at a molecular level. A number of different new approaches to understand the different genes and cytokines involved in the early identification of 
A

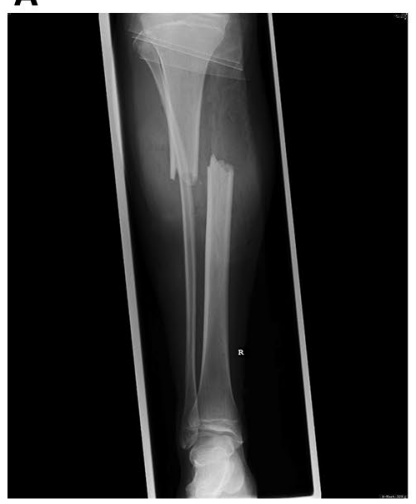

B

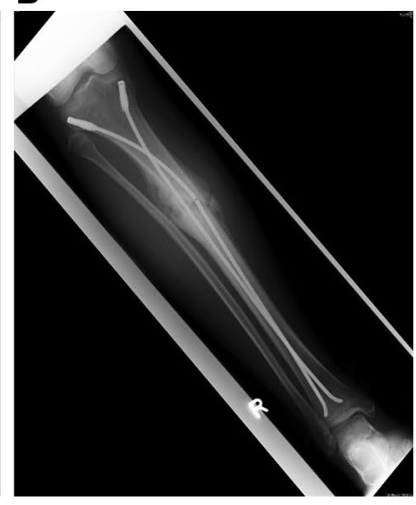

Fig. 1 a Fourteen-year-old girl had an accident as a passenger on a scooter resulting in a displaced first degree open transverse tibial shaft fracture. b Six months after closed reduction and internal fixation using two Elastic Stable Intramedullary Nails (ESIN) including locking with end caps, hypertrophic aseptic tibial shaft nonunion and subsequent nail breakage was assessed. c Surgical revision was
C

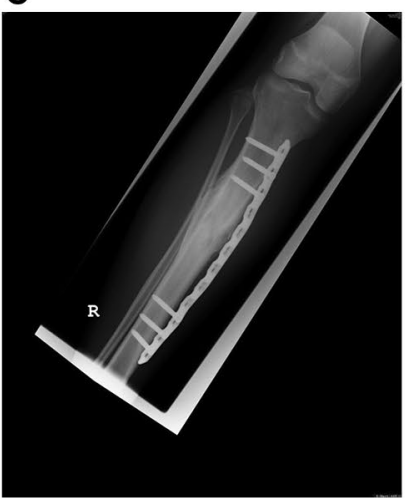

D

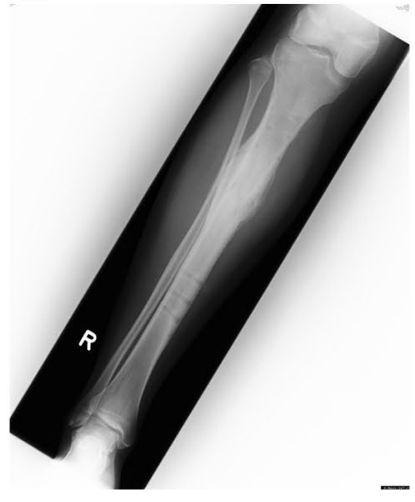

performed including debridement of the nonunion site, internal compression plate fixation and autologous cancellous bone grafting from the surrounding area. $\mathbf{d}$ Six weeks after revision surgery, radiological follow-up demonstrated osseous healing resulting in complete metal removal

C

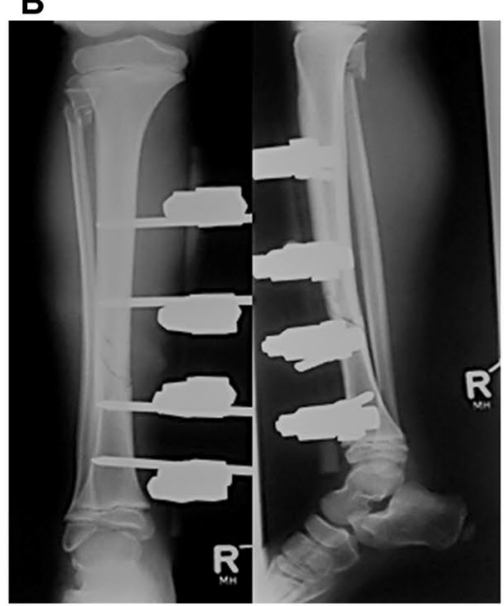

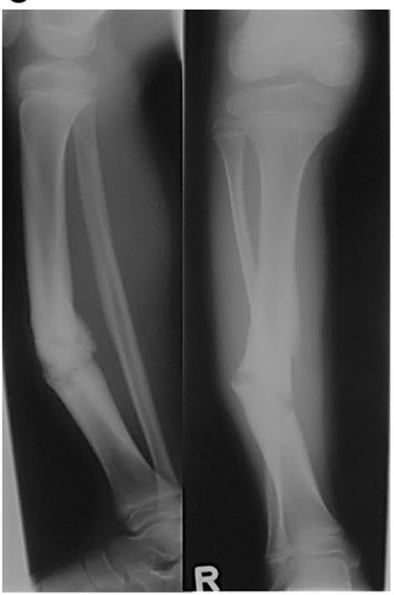

D

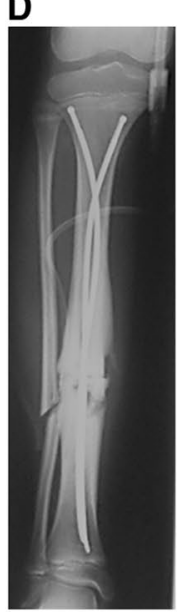

E

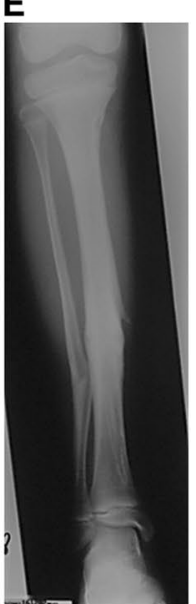

Fig. 2 a A bike accident in a 10-year-old boy resulted in Gustilo grade II open tibial shaft fracture. b Index surgery was performed with closed reduction and external fixation. The external fixation was removed after ten weeks. In the further clinical course pain occurred during full weight bearing. c Radiological follow-up demonstrated aseptic tibial shaft nonunion accompanied by varus axis deviation. $\mathbf{d}$ Revision surgery was performed with reaming of the nonunion site, fibula osteotomy, and closed tibial shaft axis correction using two ESIN. e Bony healing was assessed 16 weeks after surgical revision leading to complete metal removal nonunion could be helpful in the prevention and treatment of nonunion. However, there are different causes for the different types of nonunion, septic and aseptic or atrophic, oligotrophic, and hypertrophic. Genetic variations and external risk factors have been identified as the main causes of abnormal cytokine expression. There is evidence that some cytokine changes are more likely to be caused by genetic mutations than by external risk factors [8]. However, there is still a lack of evidence in this regard through validation in animal and human studies, as well as for the interaction and coordination between gene variations and external risk factors and for the correlation between different cytokines in the development of fracture nonunion.

A further influencing factor is that in children open reduction and internal fixation has a negative effect on fracture healing if the fixation material is incorrectly selected and interferes with fracture healing [9]. Negatively influencing factors such as the selection of the wrong osteosynthesis, inadequate fracture fixation, or infection play a decisive role in the development of tibial nonunion after surgery. This is confirmed by the data of the current study. Indications for surgical therapy should therefore be considered and limited 
A

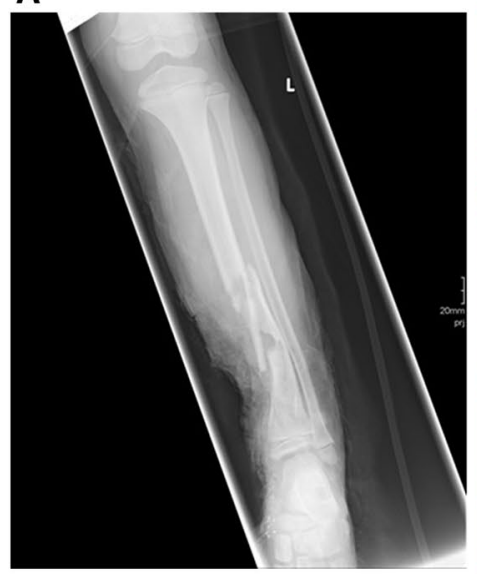

D
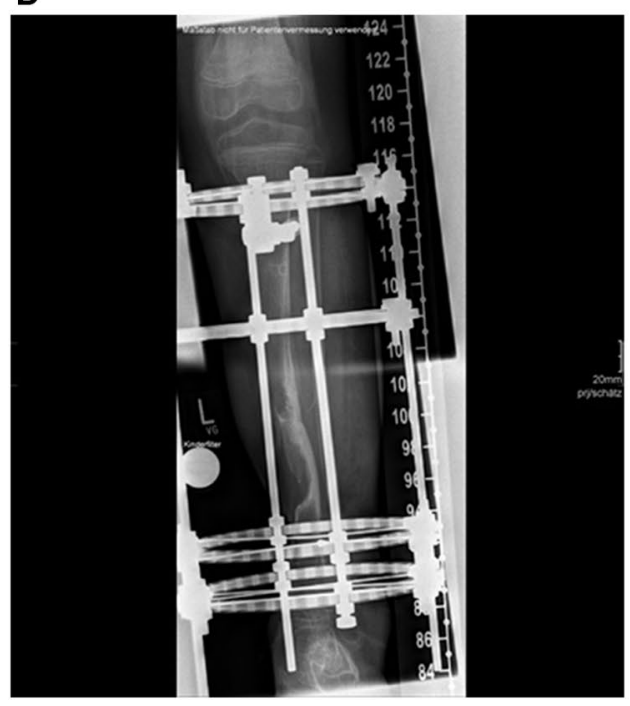

B

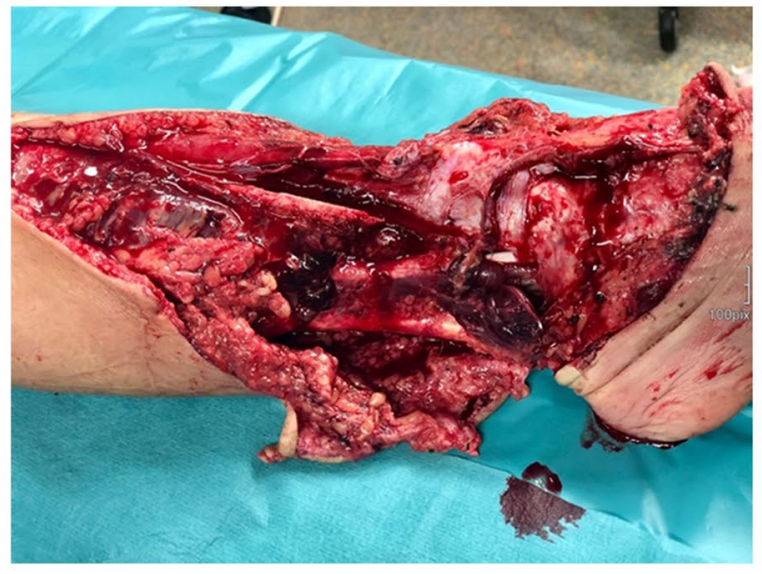

C

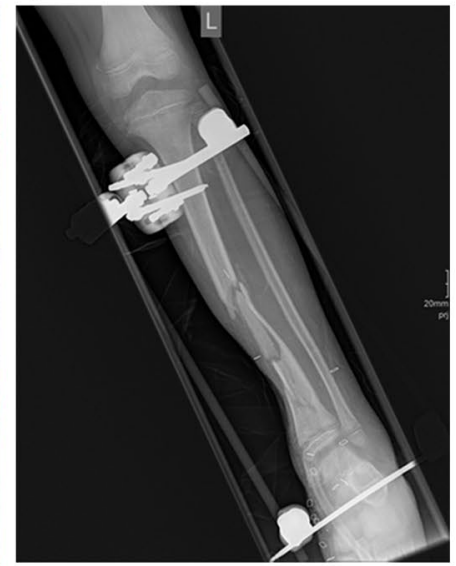

E

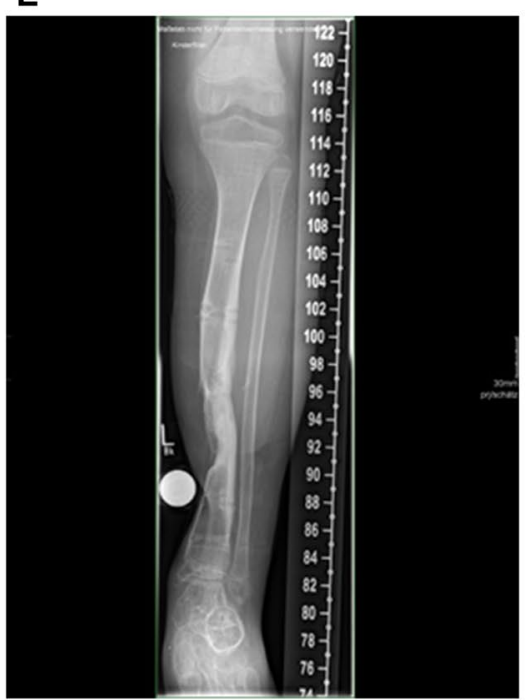

$\mathbf{F}$

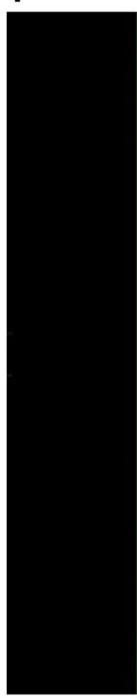

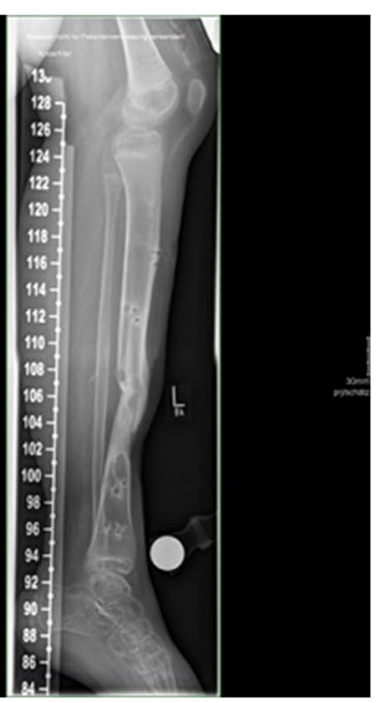

Fig. 3 a, b Eight-year-old boy rolled over by a school bus resulting in Gustilo grade IIIB open multi-fragmentary tibial fracture. c Primary treatment including closed fracture reduction and stabilization by means of an external fixator. Nonunion was defined after lack of bone healing for 6 months. d Surgical revision with construction of an Ilizarov ring fixator enabled loading. e, f Osseous healing of the defect was found radiologically and clinically 12 months after surgical revision

During the collection of data, an interesting special case was observed. During course of treatment the patient was re-diagnosed with a CPT instead of a common tibial shaft nonunion [40]. In this case, the morphology of the fibula could have made one skeptical. One may learn from this case that it is worthwhile considering the possibility of a CPT. Besides, gradual deformity correction by distraction osteogenesis is considered to be a conventional surgical management strategy not only in cases of CPT, but for lower leg fracture nonunion in general [41]. In cases with significant multi-planar deformities, it requires careful pre-operative planning and execution, which involves long periods of "dynamic" phases of the Ilizarov method [42-44].

Finally, another decisive factor in the treatment of pediatric tibial fractures is the correct aftercare treatment. In 
the growing skeleton, different basic considerations than in adults are necessary. The age-related activity level and compliance of the patient must be taken into account as well as the growth potential of the bone. Therefore, errors in aftercare treatment as well as in the indication for too early or too late metal removal can also lead to delayed union or nonunion $[45,46]$.

\section{Conclusion}

The occurrence of delayed fracture union or nonunion of the lower leg in children is very rare, but in adolescents with adult-like physique it is of the same order of magnitude as in adults. The decisive factor is a therapy appropriate to the age group, which includes a conservative or surgical approach as well as consistent follow-up treatment. Essential factors such as loss of bone substance or skin and soft tissue defects may lead to the development of nonunion despite careful therapy. Nevertheless, if the treatment principles of the growing skeleton are followed consistently, aseptic lower leg nonunion remains a rare complication in fracture management of children and adolescents.

Author contributions Study conception and design: CvR, DS. Acquisition, analysis and/or interpretation of data: all authors. Drafting/revision of the work for intellectual content and context: CvR, DS. All authors read and approved the final manuscript.

Funding Open access funding provided by Paracelsus Medical University.

Data availability The datasets analyzed during the current work are available from the corresponding author upon reasonable request.

\section{Compliance with ethical standards}

Conflict of interest All authors declare that they have no conflict of interest.

Ethical approval All procedures performed in studies involving human participants were in accordance with the ethical standards of the institutional research committee and with the 1964 Helsinki declaration and its later amendments or comparable ethical standards. All information was completely anonymized.

Consent for publication All patients who may be identified by means of images or by other information within the manuscript have given their written consent for publication.

Open Access This article is licensed under a Creative Commons Attribution 4.0 International License, which permits use, sharing, adaptation, distribution and reproduction in any medium or format, as long as you give appropriate credit to the original author(s) and the source, provide a link to the Creative Commons licence, and indicate if changes were made. The images or other third party material in this article are included in the article's Creative Commons licence, unless indicated otherwise in a credit line to the material. If material is not included in the article's Creative Commons licence and your intended use is not permitted by statutory regulation or exceeds the permitted use, you will need to obtain permission directly from the copyright holder. To view a copy of this licence, visit http://creativecommons.org/licenses/by/4.0/.

\section{References}

1. Patel NK, Horstman J, Kuester V, Sambandam S, Mounasamy V. Pediatric tibial shaft fractures. Indian J Orthop. 2018;52(5):522-8.

2. Herman MJ, Martinek MA, Abzug JM. Complications of tibial eminence and diaphyseal fractures in children: prevention and treatment. J Am Acad Orthop Surg. 2014;22(11):730-41.

3. Lovejoy SA, Mehlman CT. The community orthopaedic surgeon taking trauma call: pediatric tibia fracture pearls and pitfalls. J Orthop Trauma. 2017;31(Suppl 6):S22-6. https://doi.org/10.1097/ BOT.0000000000001017.

4. Sanders R, Swiontkowski MF, Nunley JA 2nd, Spiegel PG. The management of fractures with soft-tissue disruptions. Instr Course Lect. 1994;43:559-70.

5. Glass GE, Pearse M, Nanchahal J. The ortho-plastic management of Gustilo grade IIIB fractures of the tibia in children: a systematic review of the literature. Injury. 2009;40(8):876-9.

6. von Rüden C, Friederichs J, Zipplies S, Langer S, Morgenstern M, Bühren $\mathrm{V}$. The role of soft tissue damage in fracture treatment. OUP. 2017;5:259-64. https://doi.org/10.3238/oup.2017.0259-0264.

7. Zhou YQ, Tu HL, Duan YJ, Chen X. Comparison of bone morphogenetic protein and autologous grafting in the treatment of limb long bone nonunion: a systematic review and meta-analysis. J Orthop Surg Res. 2020;15(1):288.

8. Ding ZC, Lin YK, Gan YK, Tang TT. Molecular pathogenesis of fracture nonunion. J Orthop Translat. 2018;14:45-56.

9. Arslan H, Subaşý M, Kesemenli C, Ersuz H. Occurrence and treatment of nonunion in long bone fractures in children. Arch Orthop Trauma Surg. 2002;122(9-10):494-8.

10. Zura R, Kaste SC, Heffernan MJ, Accousti WK, Gargiulo D, Wang $\mathrm{Z}$, Steen RG. Risk factors for nonunion of bone fracture in pediatric patients: an inception cohort study of 237,033 fractures. Medicine (Baltimore). 2018;97(31):e11691.

11. Liow RY, Montgomery RJ. Treatment of established and anticipated nonunion of the tibia in childhood. J Pediatr Orthop. 2002;22(6):754-60.

12. Thunold J, Varhaug JE, Bjerkest T. Tibial shaft fractures treated by rigid internal fixation: the early results in a 4-year series. Injury. 1975;7(2):125-33.

13. Shah SB, Mishra AK, Chalise P, Shah RK, Singh RP, Shrivatava MP. Outcome of treatment of nonunion tibial shaft fracture by intramedullary interlocking nail augmentated with autogenous cancellous bone graft. Nepal Med Coll J. 2014;16(1):58-62.

14. Karaman I, Halici M, Kafadar IH, Guney A, Oner M, Gurbuz K, Karaman ZF. Mid-term results of the elastic intramedullary nailing in paediatric long bone shaft fractures: a prospective study of 102 cases. J Pediatr Orthop B. 2014;23(3):212-20.

15. Zura R, Braid-Forbes MJ, Jeray K, Mehta S, Einhorn TA, Watson JT, Della Rocca GJ, Forbes K, Steen RG. Bone fracture nonunion rate decreases with increasing age: a prospective inception cohort study. Bone. 2017;95:26-32.

16. Kołecka E, Niedzielski KR, Lipczyk Z, Flont P. Treatment of the femoral, tibia and humeral shaft fractures in children with the use of intramedullary nailing or external fixation, a long term study. Chir Narzadow Ruchu Ortop Pol. 2009;74(3):139-44. 
17. Heo J, Oh CW, Park KH, Kim JW, Kim HJ, Lee JC, Park IH. Elastic nailing of tibia shaft fractures in young children up to 10 years of age. Injury. 2016;47(4):832-6.

18. Cravino M, Canavese F, De Rosa V, Marengo L, Samba A, Rousset M, Mansour Khamallah M, Andreacchio A. Outcome of displaced distal tibial metaphyseal fractures in children between 6 and 15 years of age treated by elastic stable intramedullary nails. Eur J Orthop Surg Trauma. 2014;24:1603-8.

19. Stenroos A, Jalkanen J, Sinikumpu JJ, Palmu S, Koskimies-Virta E, Laaksonen T, Nietosvaara Y. Treatment of unstable pediatric tibia shaft fractures in Finland. Eur J Pediatr Surg. 2019;29(3):247-52.

20. Pandya NK, Edmonds EW. Immediate intramedullary flexible nailing of open pediatric tibial shaft fractures. J Pediatr Orthop. 2012;32(8):770-6.

21. Hosny GA, Ahmed AA. Infected tibial nonunion in children: is radical debridement mandatory? Injury. 2019;50(2):590-7.

22. Cullen MC, Roy DR, Crawford AH, Assenmacher J, Levy MS, Wen D. Open fracture of the tibia in children. J Bone Jt Surg Am. 1996;78(7):1039-47.

23. Song KM, Sangeorzan B, Benirschke S, Browne R. Open fractures of the tibia in children. J Pediatr Orthop. 1996;16(5):635-9.

24. Bartlett CS 3rd, Weiner LS, Yang EC. Treatment of type II and type III open tibia fractures in children. J Orthop Trauma. 1997;11(5):357-62.

25. Weber BG, Cech O. Pseudarthrosis. New York: Grune and Stratton; 1976.

26. Gustilo RB, Mendoza RM, Williams DN. Problems in management of type III (severe) open fractures: a new classification of type III open fractures. J Trauma. 1984;24:742-6.

27. Bhan K, Tyagi A, Kainth T, Gupta A, Umar M. Reamed exchange nailing in nonunion of tibial shaft fractures: a review of the current evidence. Cureus. 2020;12(7):e9267.

28. Bell A, Templeman D, Weinlein JC. Nonunion of the femur and tibia: an update. Orthop Clin N Am. 2016;47(2):365-75.

29. Crawford AH, Bagamery N. Osseous manifestations of neurofibromatosis in childhood. J Pediatr Orthop. 1986;6:72-88.

30. Bauer T, Klouche S, Grimaud O, Lortat-Jacob A, Hardy P. Treatment of infected non-unions of the femur and tibia in a French referral center for complex bone and joint infections: outcomes of 55 patients after 2 to 11 years. Orthop Traumatol Surg Res. 2018;104(1):137-45.

31. Kreder HJ, Armstrong P. A review of open tibia fracture in children. J Pediatr Orthop. 1995;15:482-8.
32. Lewallen R, Peterson HA. Nonunion of long bone fractures in children: a review of 30 cases. J Pediatr Orthop. 1985;5:135-42.

33. Mashru RP, Herman MJ, Pizzutillo PD. Tibial shaft fractures in children and adolescents. J Am Acad Orthop Surg. 2005;13(5):345-52.

34. Rodriguez-Merchan EC, Forriol F. Nonunion: general principles and experimental data. Clin Orthop Relat Res. 2004;419:4-12.

35. Grimard G, Naudie D, Laberge LC, Hamdy RC. Open fractures of the tibia in children. Clin Orthop. 1996;332:62-70.

36. Calkins MS, Burkhalter W, Reyes F. Traumatic segmental bone defects in the upper extremity. Treatment with exposed grafts of corticocancellous bone. J Bone Jt Surg Am. 1987;69:19-27.

37. Hausmann M, Ehnert S, Hofmann V, Döbele S, Freude T, Stöckle U, Nussler A. use of bone morphogenetic proteins (BMPs) for the treatment of pseudarthroses - efficiency and therapy failure. Z Orthop Unfall. 2014;152(2):144-51.

38. Högel F, Gerber C, Bühren V, Augat P. Reamed intramedullary nailing of diaphyseal tibial fractures: comparison of compression and non-compression nailing. Eur J Trauma Emerg Surg. 2013;39:73-7.

39. Younger EM, Chapman MW. Morbidity at bone graft donor sites. J Orthop Trauma. 1989;3:192-5.

40. Shah H, Rousset M, Canavese F. Congenital pseudarthrosis of the tibia: Management and complications. Indian J Orthop. 2012;46(6):616-26.

41. Ömeroğlu H. Basic principles of fracture treatment in children. Eklem Hastalik Cerrahisi. 2018;29(1):52-7.

42. Subramanyam KN, Mundargi AV, Reddy PS, Bhoskar RN. Compression osteosynthesis - an effective solution for hypertrophic nonunion of tibia in children. J Orthop Case Rep. 2018;8(6):61-4.

43. Paley D, Catagni MA, Argnani F, Villa A, Benedetti GB, Cattaneo R. Ilizarov treatment of tibial nonunions with bone loss. Clin Orthop Relat Res. 1989;241:146-65.

44. Catanzano AA Jr, Fitch RD. The use of distraction osteogenesis and a Taylor spatial frame in the treatment of a tibial shaft nonunion and deformity in a pediatric patient with osteopetrosis: a case report. JBJS Case Connect. 2018;8(4):e93-4.

45. Levy AS, Wetzler M, Lewars M, Bromberg J, Spoo J, Whitelaw GP. The orthopedic and social outcome of open tibia fractures in children. Orthopedics. 1997;20:593-8.

46. Rupp M, Biehl C, Budak M, Thormann U, Heiss C, Alt V. Diaphyseal long bone nonunions-types, aetiology, economics, and treatment recommendations. Int Orthop. 2018;42(2):247-58. 